\title{
Inspiration
}

\section{Maggie's Centres}

Edwin Heathcote

Financial Times, London

Edwin Heathcote architecture critic

Correspondence to: edwinheathcote@ hotmail.com

BMJ 2006;333:1304-5
There is something profoundly depressing about the spaces in which we experience our most momentous, traumatic, emotional, and joyous moments. Hospitals, the buildings in which we are born and sometimes experience the birth of our own children, in which we may die, and in which, as a rapidly ageing population, we will be spending an increasingly large proportion of our lives, are grim.

It was the grinding spiritual and aesthetic poverty that spurred Maggie Keswick Jencks into thinking there must be an alternative. Her legacy is an extraordinary collection of centres throughout the United Kingdom that attempt to lift the soul not only through the sympathetic professional advice and listening of the trained oncology nurses who staff them but through architecture, through the redemptive power of space, light, and sculptural form.

There are no great claims being made for this approach. Architecture does not and cannot heal cancer. Much research has linked views of trees, greenery, the sky, and natural light with quicker healing, but most of it is common sense: people feel better in nice spaces. I once heard a beautiful story. A man lies in a hospital bed but can't see out of the window at the end of the room so the fellow in the bed next to the window tells him all about what he sees. He tells him about the life on the street, the children playing, the girls walking by, the women hanging out their washing, about the traffic, the clouds and the changing weather. Dropping in and out of consciousness it is these images that keep him alive but sadly the occupant of the window bed dies. Though upset, his friend thinks at least he'll now get the bed by the window, which he does. He is amazed to see that the window looks out on to a blank brick wall.

\section{The power of imagination}

The Maggie's Centres are an attempt to convey the power of that imagination into built form; wonderful buildings making the most of little things-views, greenery, the changing sky, or nearby water. But how much can hospitals learn from these architectural gems? These are small, complementary buildings, placed within existing cancer centres. They have none of the overwhelming logistical or functional programmes of their neighbours and, as a charity, are free of the NHS's bureaucracy and grinding cost constraints.

What they can do, however, is attempt to use architecture to lift the soul. It was Maggie herself who laid the groundwork for the first centre, which opened in the grounds of the Western General Hospital in

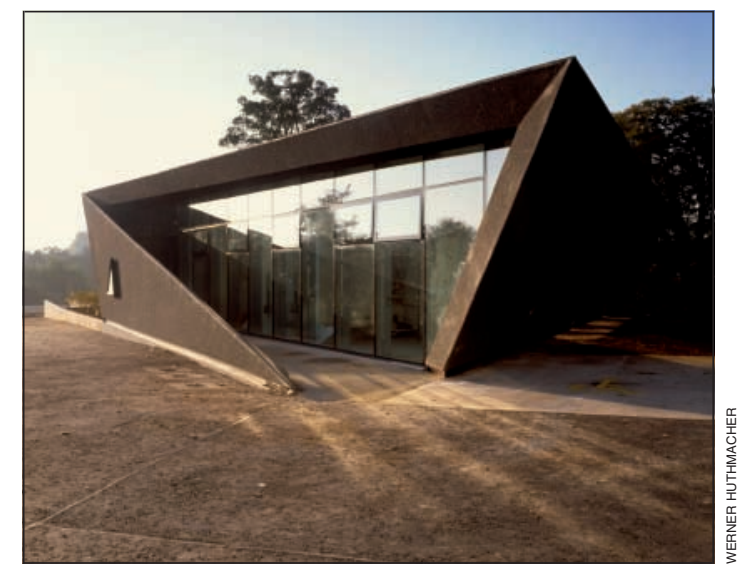

Kirkcaldy centre, designed by Zaha Hadid

Edinburgh 10 years ago, a year after she died from cancer. She had started the fundraising process for the charity that became Maggie's Centres, which was continued by her husband Charles Jencks, a renowned architectural critic who was pivotal in the promulgation of the culture of postmodern architecture and has been an eloquent defender of architecture's role as a symbolic and spiritual art as well as a purely functional one.

The centres that have been built so far were designed by a group of architects, most of whom knew the Jenckses well. The first centre, a modest converted stable building, was designed by Edinburgh architect Richard Murphy and embodies the kind of intimate scale and kitchen table domesticity that was intended as an antidote to the sterile bureaucratic corridors of conventional hospitals. It has since been expanded but maintains its smallness, intimacy, and distinctive mix of activity and quiet, a place in which people can come between appointments, wait for treatments, sit and relax with family, friends, or fellow patients and make themselves a cup of tea.

The day I visited, the centre was inhabited by people most of whom had finished their treatments but who kept coming to see friends. Like all the subsequent buildings, the centre has no front desk, it is intended to be accessible and informal, with no appointments necessary. It is a place where people begin to help themselves and others, where, although there is expert help at hand, people take control of their own circumstances, again an antidote to the traditional hospital in which the relationship is governed by an (inevitably) uneven distribution of knowledge and power, in which patients can be intimidated and tongue tied, forgetting to ask the right questions, pressured by time. 
The centres have tried to embody this radically different set of relationships in built form. Of course there is nothing new in attempting to use architecture as a balm. From the exquisite hospitals of Renaissance Italy to the powerful formality of Paris's Invalides or Wren's Royal Hospital at Greenwich, there is a long history of buildings appealing to the soul as well as healing the body. Many recent studies have attempted to show that natural light, views, art, and good architecture all play a part in patients' recovery. And there are a few scattered examples of fine design from the REHAB centre in Basle designed by Herzog and de Meuron (architects of Tate Modern) to the recent Evelina Children's Hospital in London by Hopkins Architects.

But these efforts remain the exceptions. My experience of cancer was one of superb treatment and sympathetic care in almost unspeakably dim architectural conditions. The relatively new (and hugely expensive) hospital in which I had my operation contained ambitious, impressive contemporary art and was a fine, spacious building. Yet with patients dying on either side I spent my days doped out on morphine, contained between a pair of kitsch plastic curtains, one printed with flowers, the other with some kind of early 1980s kitchen wallpaper design. The stunning view over London's rooftops remained stubbornly invisible and the opening windows remained unopened.

\section{The scale of achievement}

This experience made me wonder what else could be done and made me sympathetic to this ideal, despite a few initial reservations about the danger of claiming too much for the power of architecture alone. And the achievements of this modest charity have been extraordinary. Two of the world's great architects received their first UK commissions for Maggie's Centres. Frank Gehry, architect of the Bilbao Guggenheim, designed a centre in Dundee, and Zaha Hadid has just completed a stunning structure not far away in Kirkcaldy.

Gehry's building sits above Dundee and bathes in reflected light from the Spay. It is a modest, subtle, and intelligent building, warm and intimate, a wonderful structure from an architect used to grand, theatrical urban gestures. It is domestic in scale but still grand in ambition, a building that embraces the user in warm timber but seems determinedly focused on the water and the landscape beyond. It also manages to remain open in plan while providing small areas for privacy.

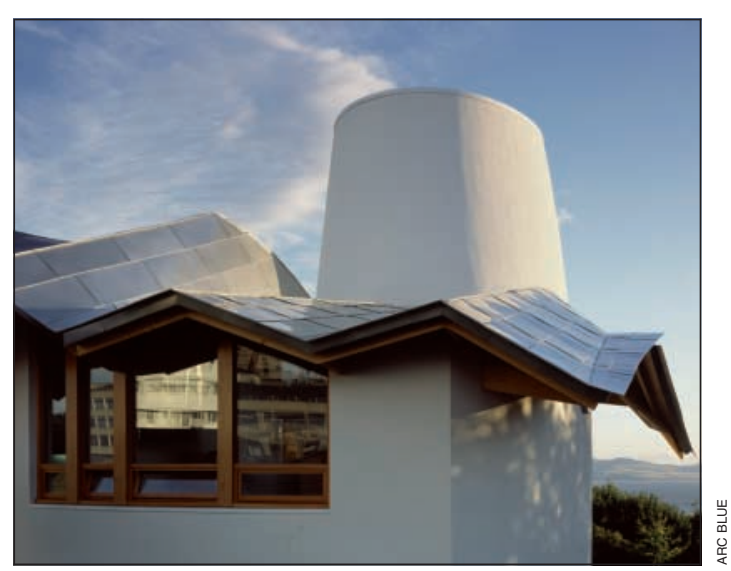

Dundee centre, designed by Frank Gehry
Hadid's building seems much tougher. Not for her the organic embrace of timber and imitation of local rendering. Instead, Hadid's structure in the car park of Kirkcaldy's Royal Victoria Hospital wraps itself in a tarmac origami shell; it grows up and wraps the user in the fabric of the ground. Sharp, angular, and futuristic it can look a little forbidding in photos but inside the jagged darkness gives way to an enveloping, curvaceous white interior cleverly sited to give views onto remarkably sylvan settings. It is self consciously theatrical. And why not? Why should spaces built to contain some of our more traumatic moments always be modest and domestic; bland and inoffensive as an old folks' dining room or a municipal crematorium?

After having done the Glasgow centre, Scottish architects Page and Park built the Maggie's Centre in the Highlands as the focus of a swirling labyrinth of landscape. Daniel Libeskind, architect and masterplanner of the bitterly contested ground zero site in New York, was going to build one in Cambridge, which seems to have fallen through. Richard Rogers (who is currently building one of the towers at ground zero) is building the newest centre, just around the corner from his Hammersmith offices, in the forecourt of the Charing Cross Hospital. Japanese architect Kisho Kurokawa is building another in Swansea, while Piers Gough is working on the centre at Nottingham.

It is an extraordinary building programme from a tiny charity. One of the obvious questions is whether this is just a fundraising ruse. But even if that is the case, who is the loser? What is the downside? Getting the world's great architects to design small buildings that are then to be entirely open to the public and that most benefit those with this rotten disease has no downside that I can think of. And while these unique centres should not be used as a stick with which to beat the NHS and conventional healthcare buildings, there is nevertheless a lesson. These are buildings that testify to the power of architecture and space. There is a long and rich history stretching from Filarete's exquisite Ospedale Maggiore in 15th century Milan to the modernist masterpieces of Alvar Aalto's Paimio Sanatorium and Berthold Lubetkin's Finsbury Health Centre.

But it is a tradition lost in the relentless quest for value and efficiency, for the bland and the inoffensive over the dramatic and the sensual. These buildings were resolutely bonded into their landscapes and that is exactly what these Maggie's Centres do. All those I spoke to who worked in these little structures were profoundly and deeply affected by their quality and the thought that went into the design.

We are currently in the midst of a huge hospital building programme. The Maggie's centre programme doesn't supply the answers to how we might change the dismal standard of most contemporary hospital architecture but it does reveal the delight, the pleasure, and the stimulation to be had from architecture. And if any of these buildings contributes to a pleasantly thoughtful or reflective moment for any of its users, a moment with friends or relatives, or a moment of hope and calm that they otherwise wouldn't have had then they have already achieved something wonderful.

Competing interests: None declared.

doi 10.1136/bmj.39062.614132.55 